\title{
Comment on: Managing tooth pain in general practice
}

Singapore Med J 2019; 60(7): 383 https://doi.org/10.11622/smedj.2019078

Dear Sir,

We would like to add some input for the medical readers regarding a recent article by Koh et al. ${ }^{(1)}$ In the article, the authors have rightly categorised tooth pain according to odontogenic and non-odontogenic causes. However, we think it would be clearer if the authors could also add additional information on referred pain, i.e. odontogenic pain that can be felt elsewhere, such as headaches, pain at the submandibular site gland region, or temporomandibular joint pain. In such situations, although the source of pain is from a tooth, pain manifests elsewhere. Such manifestations may drive patients to visit medical practitioners for a cure instead.

When we did a study among healthcare workers, traditional medical practitioners, and patients in Malaysia in 2007, we were surprised to find that visits to non-dentists to treat tooth pain was common. We herein share our finding, which was never published. We randomly interviewed 20 general medical doctors, 20 pharmacists, 15 Chinese medicine practitioners (sinsehs), five acupuncturists, five Malay shamans (bomohs), five homeopathy practitioners, five night market/grocery shop sellers and five individuals. Participants were asked to indicate their experiences on management of toothache. We found that all of them had dealt with patients seeking a cure for toothache.

We found that almost all (95\%) medical doctors and all (100\%) pharmacists prescribed analgesics for toothache. Meanwhile, $15.8 \%$ of the medical doctors added antibiotics. About $10.5 \%$ of medical doctors and $20.0 \%$ of pharmacists added other agents such as Diflam ${ }^{\mathrm{TM}}$, Oralaid ${ }^{\mathrm{TM}}$, Zantac $^{\mathrm{TM}}$, clove oil, and enzymes (papase or lysozyme) along with their analgesic(s) prescription. Thus, the article by Koh et al is timely, as it specifically provides an update for medical practitioners on the indication for antibiotic prescriptions for tooth pain. For non-professionals, we found that sinsehs most commonly prescribed paracetamol and herbs. The Malay shamans usually recommended incantation water and herbs. Belladonna was most frequently used by homoeopathists, while acupuncturists manipulated certain meridian points to relieve toothache. Even the night market/grocery shop sellers offered whatever remedy they had, some of which appeared to be unregistered drugs.

In conclusion, we found that our respondents normally tried to offer some form of treatment and that they usually treated toothache based on their training and personal experiences. Because of this, we applaud the article by Koh et al, ${ }^{(1)}$ as it will hopefully assist the medical practitioners better in their role as the primary source of treatment for any pain in the head and neck region.

Yours sincerely,

Wei Cheong $\underline{\text { Ngeow }}^{1}$, Wen Lin $\underline{\text { Chai }}^{2}$

${ }^{1}$ Department of Oral and Maxillofacial Clinical Sciences, ${ }^{2}$ Department of Restorative Dentistry, Faculty of Dentistry, University of Malaya, Malaysia. ngeowy@um.edu.my

\section{Acknowledgement}

We acknowledge the effort and work put in by our then dental students, F Zuhra Romali and H Isnin in undertaking this elective project.

\section{References}

1. Koh SWC, Li CF, Loh JSP, Wong ML, Loh VWK. Managing tooth pain in general practice. Singapore Med J 2019; 60:224-8. 